\title{
Corticostriatal and Thalamostriatal Synapses Have Distinctive Properties
}

\author{
Jun Ding, ${ }^{*}$ Jayms D. Peterson, ${ }^{\star}$ and D. James Surmeier \\ Department of Physiology, Feinberg School of Medicine, Northwestern University, Chicago, Illinois 60611
}

\begin{abstract}
The two principal excitatory glutamatergic inputs to striatal medium spiny neurons (MSNs) arise from neurons in the cerebral cortex and thalamus. Although there have been many electrophysiological studies of MSN glutamatergic synapses, little is known about how corticostriatal and thalamostriatal synapses differ. Using mouse brain slices that allowed each type of synapse to be selectively activated, electrophysiological approaches were used to characterize their properties in identified striatopallidal and striatonigral MSNs. At corticostriatal synapses, a single afferent volley increased the glutamate released by a subsequent volley, leading to enhanced postsynaptic depolarization with repetitive stimulation. This was true for both striatonigral and striatopallidal MSNs. In contrast, at thalamostriatal synapses, a single afferent volley decreased glutamate released by a subsequent volley, leading to a depressed postsynaptic depolarization with repetitive stimulation. Again, this response pattern was the same in striatonigral and striatopallidal MSNs. These differences in release probability and short-term synaptic plasticity suggest that corticostriatal and thalamostriatal projection systems code information in temporally distinct ways, constraining how they regulate striatal circuitry.
\end{abstract}

Key words: striatum; medium spiny neuron; glutamatergic synapse; corticostriatal synapse; thalamostriatal synapse; release probability; short-term plasticity

\section{Introduction}

Although most models of the basal ganglia emphasize the importance of the connection from the cerebral cortex to the striatum, the thalamus also has strong connections with the striatum (Berendse and Groenewegen, 1990; Smith et al., 2004). Anatomical studies suggest that corticostriatal and thalamostriatal synapses formed on principal medium spiny neurons (MSNs) are nearly equal in number, with corticostriatal synapses only being modestly more numerous (Smith et al., 2004). These synapses are critical to activity patterns in MSNs, controlling transitions from quiescent, hyperpolarized states (down states) to depolarized states (up states) where MSNs spike (Wilson, 1993). Studies performed in vivo have shown that oscillations in cortical activity are strongly correlated with MSN state transitions, suggesting that these extended periods of depolarization depend on sustained excitatory activity at corticostriatal synapses (Stern et al., 1997). Although thalamic activity is clearly correlated with striatal activity in vivo (Matsumoto et al., 2001; Minamimoto and Kimura, 2002), much less is known about how this activity influences MSN state transitions.

A clear picture of the functional properties of these two syn-

\footnotetext{
Received 0ct. 22, 2007; revised April 28, 2008; accepted May 5, 2008.

This work was supported by National Institutes of Health Grant NS34696 (D.J.S.) and the Picower Foundation (D.J.S.). We thank Qing Ruan, Karen Saporito, and Sasha Ulrich for excellent technical assistance.

*J.D. and J.D.P. contributed equally to this work.

Correspondence should be addressed to Dr. D. James Surmeier, Department of Physiology, Feinberg School of Medicine, Northwestern University, 303 East Chicago Avenue, Chicago, IL 60611. E-mail: j-surmeier@northwestern.edu.

J. Ding's present address: Department of Neurobiology, Harvard Medical School, Boston, MA 02115

DOI:10.1523/JNEUROSCI.0435-08.2008

Copyright $\odot 2008$ Society for Neuroscience $\quad$ 0270-6474/08/286483-10\$15.00/0
}

apses would be of obvious value in sorting out their role in regulating striatal activity. But surprisingly little is known on this score, reflecting the limitations of in vitro approaches used to obtain this kind of information. In conventional coronal brain slices, the axons of both cortical and thalamic neurons are cut a short distance from their cell bodies, making it impossible to stimulate outside the striatum and selectively activate one or the other axonal class (Kawaguchi et al., 1989). Furthermore, corticostriatal and thalamostriatal synapses are intermingled on the dendritic trees of MSNs (Wilson, 2004), making local stimulation an ineffective strategy for selective activation of one synaptic class. Another impediment to gaining a clear picture of how these synapses shape striatal activity is the heterogeneity of MSNs. In the striatum, there are two major classes of MSN that can be distinguished on the basis of $\mathrm{D}_{1}$ and $\mathrm{D}_{2}$ dopamine (DA) receptor expression and axonal projection (Gerfen, 1989; Surmeier et al., 1996). The cortical and thalamic neurons projecting to these two MSN populations are not completely overlapping (Sidibe and Smith, 1996; Lei et al., 2004; Hoshi et al., 2005), raising the possibility that the functional properties of their corticostriatal and thalamostriatal synapses differ. In fact, recent work using transgenic mice in which MSN subtypes are labeled with green fluorescent protein (GFP) suggests that the release probability of glutamatergic synapses formed on $D_{1}$ receptor-expressing striatonigral and $\mathrm{D}_{2}$ receptor expressing striatopallidal MSNs differ (Kreitzer and Malenka, 2007).

To begin to fill this gap in our understanding, electrophysiological studies were performed with oblique horizontal brain slices that permitted selective activation of corticostriatal or thalamostriatal axons (Smeal et al., 2007). To address striatal heterogeneity, slices were obtained from the brains of mice in 
which $\mathrm{D}_{1}$ or $\mathrm{D}_{2}$ receptor-expressing MSNs were labeled with GFP (Heintz, 2001; Day et al., 2006). The studies revealed that, in both types of MSN, corticostriatal synapses had a relatively low release probability and were facilitated by repetitive stimulation; in contrast, thalamostriatal synapses in both cell types had a high release probability and were depressed by repetitive stimulation.

\section{Materials and Methods}

Horizontal brain slice. Coronal, parasagittal and oblique horizontal brain slices $(275-300 \mu \mathrm{m})$ were obtained from 21- to 31-d-old bacterial artificial chromosome (BAC) $D_{1}$ and $D_{2}$ GFP mice using standard techniques (Wang et al., 2006). The horizontal slice preparation was similar to that described previously (Smeal et al., 2007). The brain was laid on a chilled cutting surface ventral side down and the cerebellum was removed. The brain was blocked along the midline and then both hemispheres laid medial side down. Then, an $\sim 20^{\circ}$ oblique horizontal cut was made on the dorsal side because single-axon tracing work suggests that thalamostriatal afferents run toward striatum in lateral, anterior, and dorsal directions (Deschenes et al., 1996). To confirm thalamostriatal afferents were preserved in the slice, we performed biocytin labeling experiment in the horizontal brain slice (supplemental Fig. 1, available at www.jneurosci.org as supplemental material). Anterior labeled thalamostriatal axons can be readily seen in the horizontal slice (supplemental Fig. 1, available at www.jneurosci.org as supplemental material). These results showed that the horizontal slice preparation used here is a reliable brain slice preparation to study corticostriatal and thalamostriatal afferents in the striatum.

Electrophysiological recording. Individual slices were transferred to a submersion-style recording chamber and continuously superfused with artificial CSF (ACSF) at a rate of $2-3 \mathrm{ml} / \mathrm{min}$ at room temperature or $32-34^{\circ} \mathrm{C}$ as stated in the text. The ACSF contained the following (in mM): $125 \mathrm{NaCl}$, $2.5 \mathrm{KCl}, 2 \mathrm{CaCl}_{2}, 1 \mathrm{MgCl}_{2}, 25 \mathrm{NaHCO}_{3}, 1.25 \mathrm{NaH}_{2} \mathrm{PO}_{4}$, and 12.5 glucose. Cell-attached, whole-cell voltage-clamp or current-clamp recordings were performed using standard techniques. For voltage-clamp experiments, pipettes (3-5 M $\Omega$ ) were filled with a $\mathrm{Cs}^{+}$internal solution containing (in $\mathrm{mM}$ ) $120 \mathrm{CsMeSO}_{3}, 15 \mathrm{CsCl}, 8 \mathrm{NaCl}, 10$ tetraethylammonium-Cl, 10 HEPES, 2-5 QX-314 [N-(2,6-dimethylphenylcarbamoylmethyl)triethylammonium bromide], 0.2 EGTA, 2 Mg-ATP, and 0.3 Na-GTP, pH 7.3 adjusted with $\mathrm{CsOH}$, and were performed at room temperature. For cell-attached and current-clamp experiments, pipettes $\left(3-5 \mathrm{M} \Omega\right.$ ) were filled with a $\mathrm{K}^{+}$internal solution consisting of (in mM) $135 \mathrm{KMeSO}_{4}, 5 \mathrm{KCl}, 0.5 \mathrm{CaCl}_{2}, 5 \mathrm{HEPES}$, 5 EGTA, 2 Mg-ATP, and $0.3 \mathrm{Na}-\mathrm{GTP}$, pH 7.3 adjusted with $\mathrm{KOH}$. These experiments were done at near physiological temperature $\left(32-35^{\circ} \mathrm{C}\right)$. For all experiments, $10 \mu \mathrm{M}$ gabazine [(-)SR95531] or $50 \mu \mathrm{m}$ picrotoxin was added to the superfusion medium to block $\mathrm{GABA}_{\mathrm{A}}$ receptor-mediated synaptic responses; $10 \mu \mathrm{M}$ (2S)-3-\{[(15)-1-(3,4-dichlorophenyl)ethyl $]$ amino-2hydroxypropyl $\}$ (phenylmethyl)phosphinic acid (CGP55845) was used to block $\mathrm{GABA}_{\mathrm{B}}$ receptor in some experiments. Recordings were obtained with a Multiclamp 700A (filter set at 2-5 kHz); signals were digitized at 10-20 $\mathrm{kHz}$. Voltage measurements were not corrected for the experimentally determined junction potential $(\sim 8-9 \mathrm{mV})$.

Stimulation (50-200 $\mu \mathrm{s})$ was performed using steel concentric electrodes (Frederick Haer). The corticostriatal afferents were stimulated by placing the stimulation electrode between layer V and VI in the cortex; thalamostriatal afferents were stimulated by placing the stimulation electrode in the thalamus close to the medial border of the thalamic reticular
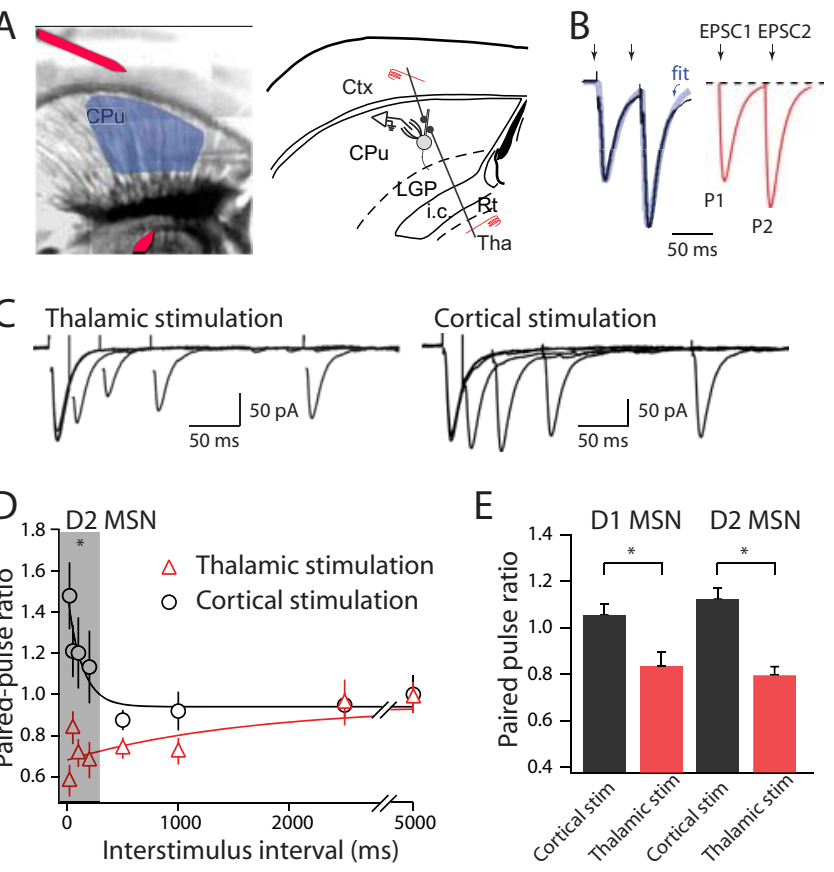

terstimulus interval (ms)

ifferent PPRs. A, Composite image of a horizontal slice and horizontal diagram of mouse brain. Medium spiny neurons are sampled from the shaded region. Stimulating electrodes in the cortex (Ctx) and thalamus (Tha) are highlighted with a red overlay. $\boldsymbol{B}$, To determine EPSC amplitudes in paired-pulse paradigms, the first EPSC was fitted with an exponential function and the amplitude of the second EPSC was measured from this baseline to (he corded from striatonigral and striatopallidal neurons with a $50 \mathrm{~ms}$ ISI. LGP, Lateral globis pallidus; i.c., internal capsule; $\mathrm{CPu}$, striatum; Rt, Reticular thalamic nucleus. Error bars indicate SEM. Asterisks indicate statistical significance.

nucleus. Synaptic potentials were evoked by just suprathreshold pulses (1.5-2× threshold) to minimize activation of neighboring white matter. Thalamic stimulus intensity was, on average, 1.5 times that of the cortical stimulus intensity. Intrastriatal stimulation was performed by placing an electrode between the recorded medium spiny neuron and cortex, typically $\sim 100-150 \mu \mathrm{m}$ from the cell body.

In the initial phase of the study, only neurons with both cortical and thalamic responses were included in the study $(n=95)$. This criterion was commonly met, but a precise count of the number of MSNs in which this did not occur was not kept. In later experiments, this criterion was dropped because there were no differences in the cortical or thalamic synaptic responses where only one of the stimulation sites yielded a response. Therefore, the data were pooled for statistical analysis. In this latter sample, $26 \%$ (15 of 57 ) of the MSNs responded reliably to both cortical and thalamic sites, $44 \%$ ( 25 of 57 ) responded just to the cortical site and 30\% (17 of 57) responded just to the thalamic site. These differences were not taken to reflect anything other than the position of the MSN and the axons that were preserved in that particular slice.

To determine EPSC amplitudes in paired-pulse paradigms with short interstimulus intervals (ISIs), the first EPSC was fitted with a biexponential, EPSC-like function $\left[A 1 \times\left(1-\exp \left(-\left(t-t_{0}\right) / \tau_{\text {rise }}\right)\right) \times \exp (-(t-\right.$ $\left.\left.\left.t_{0}\right) / \tau_{\text {decay }}\right)\right]$, and the amplitude of the second EPSC was determined after subtracting the first EPSC. To determine EPSC amplitudes in $50 \mathrm{~Hz}$ high-frequency stimulation train, the EPSCs (five stimuli, $50 \mathrm{~Hz}$ ) were fitted with a sum of five biexponential functions of the same form with appropriate time delays. The kinetics of the EPSCs $\left(\tau_{\text {rise }}, \tau_{\text {decay }}\right)$ were assumed to be constant, with only the amplitude $\left(A_{i}\right)$ varying as a function of pulse number. EPSCs early in the trains were well fit with this constraint, but the decay phase of the last EPSC often had a slower component. This allowed individual EPSCs amplitude to be estimated without contamination from preceding EPSCs. Estimates of EPSC amplitude from the fits were measured and plotted against stimulus number. 
A

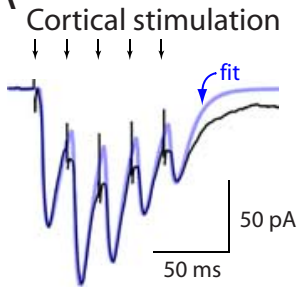

C

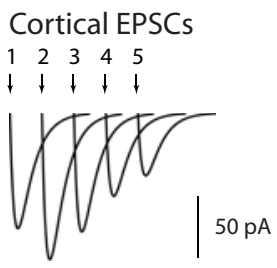

Thalamic stimulation $\downarrow \downarrow 1 \downarrow \downarrow$

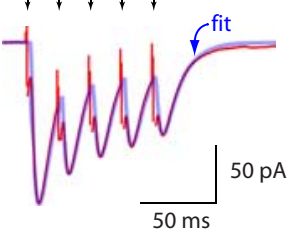

Thalamic EPSCs

$\begin{array}{llllll}1 & 2 & 3 & 4 & 5\end{array}$

$1+1+1$

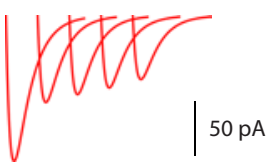

B

Normalized

$1+1+1$
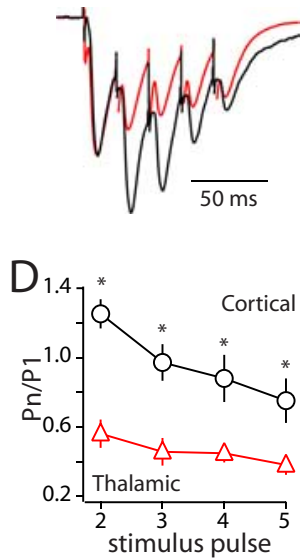

Figure 2. Stimulus trains further differentiate corticostriatal and thalamostriatal synaptic plasticity. $\boldsymbol{A}$, Whole-cell voltageclamp recordings of EPSCs elicited by train stimulation ( $50 \mathrm{~Hz}, 5$ pulses). EPSCs were fitted with five double-exponential functions (blue traces). $\boldsymbol{B}$, Normalized EPSCS elicited by train stimulation. C, Each individual EPSC was generated and plotted based on fitted values. D, Fit EPSC amplitudes normalized to the first EPSC amplitude and plotted against stimulus number $(50 \mathrm{~Hz})$. Error bars indicate SEM. Asterisks indicate statistical significance.

In experiments where $\mathrm{Ca}^{2+}$ was replaced with $\mathrm{Sr}^{2+}$, AMPA-mediated quantal events were collected during a $300 \mathrm{~ms}$ period beginning $50 \mathrm{~ms}$ after each stimulus (delivered once every $30 \mathrm{~s}$ ) in an external solution containing D-APV $(50 \mu \mathrm{M})$ and MK-801 [(5S,10R)-(+)-5-methyl10,11-dihydro-5H-dibenzo[a,d]cyclohepten-5,10-imine] $(20 \mu \mathrm{M}), 2 \mathrm{mM}$ $\mathrm{Sr}^{2+}$, and $0 \mathrm{Ca}^{2+}$. Quantal events were analyzed using Minianalysis software (Synaptosoft) with detection parameters set at $>5 \mathrm{pA}$ amplitude and individually verified. For each cell, at least 300 miniature EPSCs (mEPSCs) were taken for constructing cumulative probability plots and calculating mean mEPSC amplitudes and $10-90 \%$ rise time and decay time.

To generate estimates of NMDA/AMPA receptor ratios, MSNs were held at $+40 \mathrm{mV}$ to relieve $\mathrm{Mg}^{2+}$ block of NMDA receptors, then cortical or thalamic stimuli were delivered to evoke EPSCs. Average EPSCs at $+40 \mathrm{mV}(\sim 10$ EPSCs $)$ in the absence and presence of D-APV $(50 \mu \mathrm{M})$ were measured. The average response in the presence of D-APV (AMPA receptor only) was subtracted from that seen in its absence and an average NMDAR EPSC calculated. The peak of the NMDA EPSC was divided by the peak of the AMPA EPSC to yield an NMDA/AMPA receptor ratio. For NR2B subunit-containing NMDA receptor (NR2B)/total NMDA receptor ratios, ifenprodil $(3 \mu \mathrm{M})$ was bath applied before D-APV application to block the current carried by NR2B receptors. The peak of the NR2B EPSC (determined by subtraction) was divided by the peak of the NMDAR EPSC to yield an NR2B/NMDA receptor ratio.

A nonstationary fluctuation analysis of evoked EPSCs was used to compute the variance of $>20$ consecutive EPSCs after cortical or thalamic stimulation. EPSCs were obtained with the extracellular $\mathrm{Ca}^{2+}$ / $\mathrm{Mg}^{2+}$ concentrations at normal levels and then at $0.5 \mathrm{mM} \mathrm{Ca}^{2+} / 2.5 \mathrm{~mm}$ $\mathrm{Mg}^{2+}$ and $4 \mathrm{~mm} \mathrm{Ca}^{2+} / 0.5 \mathrm{~mm} \mathrm{Mg}^{2+}$. EPSC mean and variance were measured from stable records in each of these conditions (Clements and Silver, 2000). Then, EPSC variance and mean amplitude were fit as described by Clements and Silver (2000).

Biocytin staining. Biocytin $(5 \mathrm{mg} / \mathrm{ml})$ was dissolved into the ACSF. A puffer pipette was placed in the thalamus along the medial border of the reticular nucleus of a parahorizontal slice containing the striatum. To reduce the diffusion of biocytin away from the injection site, biocytin (5 $\mathrm{mg} / \mathrm{ml}$ )-containing ACSF was puffed in a series of short pulses in the thalamus for $30 \mathrm{~min}$ at $34^{\circ} \mathrm{C}$ to allow thalamic neurons to take up biocytin. The direction of the slice superfusion was established in such a way as to increase specificity and minimize movement of the biocytin toward the internal capsule and globus pallidus. Slices were then held for another $30 \mathrm{~min}$ at room temperature in a holding chamber where they were completely submerged in ACSF bubbled with $95 \% \mathrm{O}_{2}$ and $5 \% \mathrm{CO}_{2}$.

Subsequently, slices were fixed overnight in $2 \%$ paraformaldehyde at $4^{\circ} \mathrm{C}$. Biocytin-filled cells were visualized using the avidin-biotin-horseradish peroxidase reaction (ABC Elite peroxidase kit; Vector Laboratories) according to the instructions of the manufacturer.

Data analysis and statistics methods. Data analysis was done with Clampfit 9.2 (Molecular Devices), Igor Pro 5.0 (WaveMetrics), and Minianalysis software (Synaptosoft). Statistical analyses were performed using Sigmastat 3.0 (SPSS). Summary data are reported as mean \pm SEM when sample sizes exceeded 10 and as medians for smaller samples where sampling distributions were less well defined. Box plots and bar graphs were used for graphic illustration of data. Nonmatched samples were analyzed with the nonparametric Mann-Whitney rank-sum test. Matched samples were analyzed with Wilcoxon signed rank test.

Reagents and chemicals. All reagents were obtained from Sigma except $\mathrm{KMeSO}_{4}$ (ICN Biochemicals), $\mathrm{Na}_{2} \mathrm{GTP}$ (Boehringer Mannheim), SR95531, D-APV, and CGP55845 (Tocris Bioscience).

\section{Results}

Horizontal slice brain preparation

\section{preserves corticostriatal and thalamostriatal axons}

Previous work by Kawaguchi et al. (1989) demonstrated that the axons of cortical pyramidal neurons projecting to the striatum could be preserved in a parahorizontal brain slice. However, it was not clear from their work whether the connectivity of thalamostriatal axons would also be maintained in this preparation (Deschenes et al., 1996). Guided by recent work by Smeal et al. (2007), we tested this possibility by injecting biocytin into the thalamus of parahorizontal slices to track the course of thalamostriatal axons. These experiments revealed that the connectivity of many thalamostriatal axons was preserved in this slice (supplemental Fig. 1, available at www.jneurosci.org as supplemental material), making it a potentially valuable preparation for studying both corticostriatal and thalamostriatal synapses.

The physiological properties of corticostriatal and thalamostriatal synapses were studied by electrically stimulating in either cortex or thalamus while recording synaptic responses in MSNs. To activate corticostriatal synapses, stimulation electrodes were placed between cortical layers V and layer VI (Fig. $1 A$ ). With this electrode placement, corticostriatal EPSCs could be reliably recorded in MSNs across a broad region of the striatum. To ensure that EPSCs evoked by cortical stimulation did not result from current spread to the striatum, a knife cut was made between the cerebral cortex and striatum. After this cut, EPSCs were not evoked by cortical stimulation (supplemental Fig. $2 \mathrm{~A}$, available at www.jneurosci.org as supplemental material). To activate thalamostriatal synapses, a second stimulation electrode was placed in the thalamus close to the medial border of the reticular nucleus (Fig. $1 \mathrm{~A}$ ). Thalamic stimulation reliably evoked EPSCs in MSNs. Again, a knife cut between the striatum and thalamus eliminated synaptic responses evoked by thalamic stimulation (supplemental Fig. 2 B, available at www.jneurosci.org as supplemental material).

\section{Corticostriatal and thalamostriatal synapses differ in PPRs}

A commonly studied form of activity-dependent plasticity is manifested by changes in the amplitude of a test EPSC produced 
by a preceding, conditioning terminal volley. A convenient quantitative measure of this plasticity is the ratio of the second (test) EPSC amplitude to the first (conditioning); this is called the paired-pulse ratio (PPR) (Fig. 1B). At short interstimulus intervals where the first EPSC and second EPSCs overlapped in time, the first EPSC was fit with a biexponential, EPSC-like waveform to properly subtract its contribution to the apparent amplitude of the second EPSC (see Materials and Methods). In $\mathrm{D}_{2}$ DA receptor-expressing striatopallidal MSNs [identified by enhanced GFP (eGFP) expression in slices from BAC $\mathrm{D}_{2}$ mice], the PPR was significantly larger than 1 with short conditioning intervals, and as the interval was increased in length, the PPR returned to 1 (Fig. $1 C, D$ ). In contrast, the PPR at thalamostriatal synapses was significantly $<1$ at short conditioning intervals (Fig. 1C,D) (corticostriatal $\mathrm{PPR}_{50 \mathrm{~ms}}, 1.13 \pm 0.05$; thalamostriatal $\mathrm{PPR}_{50 \mathrm{~ms}}, 0.80 \pm 0.04 ; n=27 ; p<0.001$, Mann-Whitney). In $\mathrm{D}_{1}$ DA receptorexpressing striatonigral MSNs (identified by eGFP expression in slices from BAC $D_{1}$ mice), the short-term plasticity of corticostriatal and thalamostriatal synapses was very similar to that found in striatopallidal MSNs (Fig. 1E) ( $p>0.05$, Mann-Whitney). The PPR of corticostriatal synapses on striatonigral MSNs was larger than 1 at short conditioning intervals $(p<0.01$, Mann-Whitney), whereas as it was consistently $<1$ at thalamostriatal synapses $(p<$ 0.001, Mann-Whitney) (Fig. $1 E$ ) (corticostriatal $\mathrm{PPR}_{50 \mathrm{~ms}}, 1.06 \pm 0.05$; thalamostriatal $\mathrm{PPR}_{50 \mathrm{~ms}}, 0.83 \pm 0.06 ; n=17 ; p<$ 0.001, Mann-Whitney).

To extend this analysis, the response to longer stimulus trains (five stimuli at 50 $\mathrm{Hz}$ ) was examined. The amplitude of individual EPSCs was estimated by fitting the synaptic response with a sum of biexponential, EPSC-like functions (Fig. 2A-C) (see Materials and Methods). Corticostriatal EPSCs first increased in amplitude (as with paired pulses) and then decreased in amplitude later in the train (Fig. 2D) (125 \pm $8.4 \%$ after second stimulus; $75.2 \pm 12.9 \%$ after fifth stimulus; $n=10)$; in contrast, thalamostriatal EPSCs steadily declined in amplitude (Fig. 2D) (56.1 $\pm 8.1 \%$ after second stimulus; $p<0.001$ compared with cortical second stimulus, Mann-Whitney; $38.1 \pm$ $5.7 \%$ after fifth stimulus; $p<0.05$ compared with cortical fifth stimulus, Mann-Whitney; $n=10$ ).

\section{Intrastriatal stimulation evokes distinctive responses in MSNs}

The data from these experiments suggest that the short-term plasticity of striatal glutamatergic synapses is a reflection of their presynaptic origin, not the type of postsynaptic MSN. To provide a test of this hypothesis, more commonly used parasagittal slices were prepared. In these brain slices, like the parahorizontal ones, many corticostriatal fibers retain their connectivity with parent

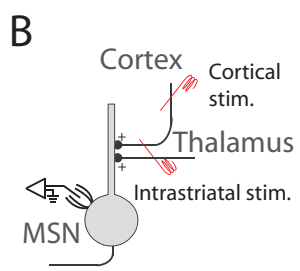

D Cortical stimulation

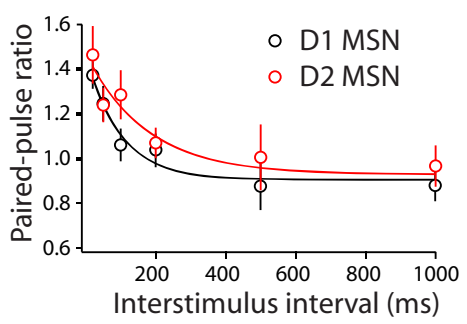

F Intrastriatal stimulation

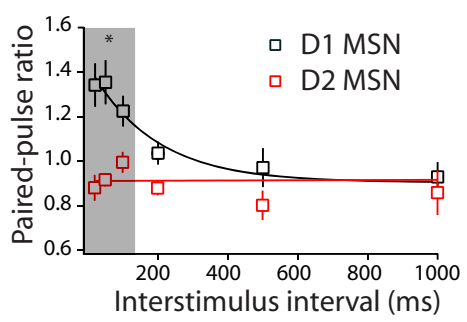

Figure 3. Intrastriatal stimulation produces distinctive short-term plasticity in striatopallidal and striatonigral MSNs. A, Composite image of a sagittal slice and sagittal diagram of mouse brain showing cortex (Ctx), striatum (CPu), lateral globus pallidus (GP), internal capsule (i.c.), corpus callosum (cc), lateral ventricle (LV), laterodorsal thalamus nucleus, ventrolateral part (LDVL), were significantly lower with intrastriatal stimulation in striatopallidal neurons compared with striatonigral neurons. Error bars indicate SEM. The asterisk indicates statistical significance.

cortical cell bodies (Vergara et al., 2003). As expected, MSN EPSCs evoked by stimulation of deep cortical layers in parasagittal slices were abolished by a knife cut between the cortex and striatum; increasing the stimulus intensity 10 -fold still failed to evoked EPSCs in cut slices, whereas local stimulation within the striatum consistently evoked a robust EPSC. In these parasagittal slices, corticostriatal EPSCs had properties indistinguishable from those evoked in parahorizontal slices, suggesting the same population of afferent fibers was being activated. Moreover, PPRs in striatonigral and striatopallidal MSNs were not significantly different (Fig. 3C,D) (in striatonigral neurons, corticostriatal $\mathrm{PPR}_{50 \mathrm{~ms}}$ median, 1.22; in striatopallidal neurons, corticostriatal $\mathrm{PPR}_{50 \mathrm{~ms}}$ median, $1.25 ; n=8 ; p>0.05$, Mann-Whitney). However, in agreement with recent work (Kreitzer and Malenka, 2007), the response of striatopallidal and striatonigral MSNs to intrastriatal stimulation was not the same. Stimulating near striatonigral MSNs $(\sim 100-150 \mu \mathrm{m})$ (Fig. $3 A$ ) yielded PPRs that were not significantly different from those generated by corticostriatal synapses (Fig. 3C-F) (corticostriatal $\mathrm{PPR}_{50 \mathrm{~ms}}$ median, 1.22; in- 

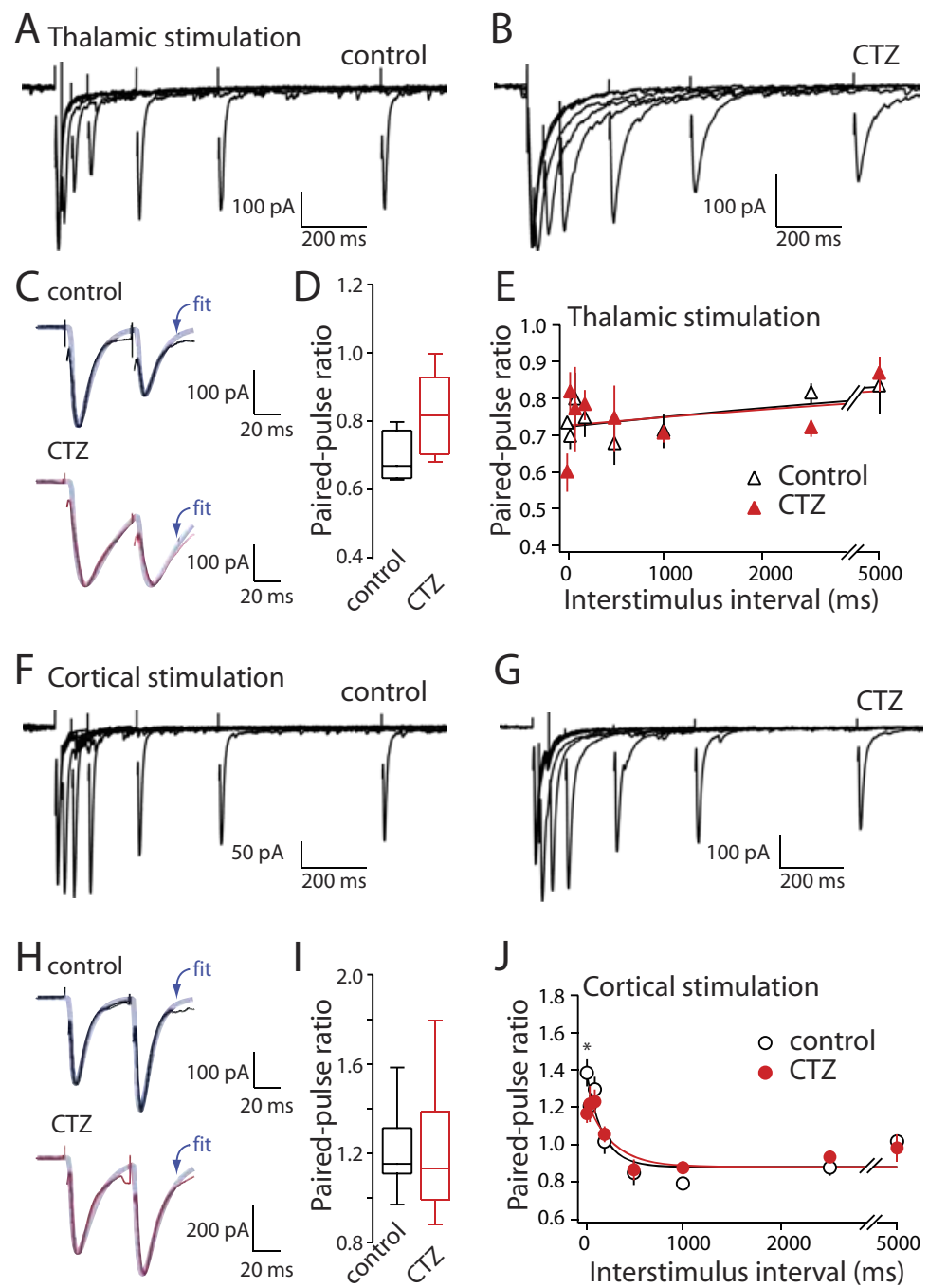

Figure 4. CTZ does not significantly alter corticostriatal and thalamostriatal EPSCSPPRs. $\boldsymbol{A}, \boldsymbol{B}$, Thalamostriatal EPSCs elicited by paired stimuli with increasing ISIs in control condition and in the presence of CTZ. C, EPSCS (holding potential, $-70 \mathrm{mV}$ ) with an ISI of 50 ms in control and CTZ. D, Box-plot summary of PPRs at an ISI of $50 \mathrm{~ms}$. $\boldsymbol{E}$, Summary graph of PPRs recorded from medium spiny neurons plotted against ISI for thalamic stimulation in control (triangles) and CTZ (filled triangles). F, G, Corticostriatal EPSCs elicited by paired stimuli in control condition and in the presence of CTZ. $\boldsymbol{H}$, EPSCS (holding potential, $-70 \mathrm{mV}$ ) with an ISI of $50 \mathrm{~ms}$ in control and (TZ. I, Box-plot summary of PPRs at an ISI of $50 \mathrm{~ms}$.J,Summary graph of PPRs recorded from medium spiny neurons plotted against ISI for cortical stimulation in control (circle) and CTZ (filled circle). Error bars indicate SEM. The asterisk indicates statistical significance.

2002). For example, desensitization of postsynaptic AMPA receptors can lead to paired-pulse depression. To test for this possibility, the impact of cyclothiazide (CTZ), a drug that slows desensitization of AMPA receptors, on corticostriatal and thalamostriatal PPRs was examined. As expected, CTZ (50-100 $\mu \mathrm{M})$ significantly increased the amplitude of both corticostriatal and thalamostriatal EPSCs (control corticostriatal EPSC amplitude, $193.7 \pm$ $34.1 \mathrm{pA}$; +CTZ, $270.8 \pm 65.2 \mathrm{pA} ; n=10$, $p<0.05$, Wilcoxon signed rank; control thalamostriatal EPSC amplitude median, 204.4 pA; + CTZ amplitude median, 280.6 $\mathrm{pA} ; n=5, p<0.05$, Wilcoxon signed rank). However, CTZ did not change the magnitude of paired-pulse depression at thalamostriatal synapses (Fig. 4C,D) (control $\mathrm{PPR}_{50}$ ms median, 0.67; +CTZ $\mathrm{PPR}_{50 \mathrm{~ms}}$ median, $0.82 ; n=5 ; p>0.05$, Wilcoxon signed rank). Thalamostriatal PPRs at other interstimulus intervals were also not significantly changed by CTZ (Fig. $4 E)(p>0.05$, Wilcoxon signed rank). Similarly, CTZ did not significantly change the PPRs at corticostriatal synapses with a $50 \mathrm{~ms}$ (or longer) interstimulus interval (Fig. $4 \mathrm{H}-J$ ) (control $\mathrm{PPR}_{50} \mathrm{~ms}$, $1.21 \pm 0.06 ;+\mathrm{CTZ} \mathrm{PPR}_{50 \mathrm{~ms}}, 1.22 \pm 0.09$; $n=10, p>0.05$, Wilcoxon signed rank). However, at shorter interstimulus interval (20 ms), CTZ significantly decreased corticostriatal PPRs (control $\mathrm{PPR}_{20 \mathrm{~ms}}, 1.38 \pm$ 0.07; + CTZ PPR $20 \mathrm{~ms}, 1.17 \pm 0.05 ; n=10$; $p<0.01$, Wilcoxon signed rank). This observation is consistent with a presynaptic effect of CTZ (Chen et al., 2002).

Although there were no differences in EPSC decay time constants at corticostriatal and thalamostriatal synapses in the absence of CTZ, in the presence of CTZ, the thalamostriatal EPSCs decay time constant was significantly longer than that of

trastriatal $\mathrm{PPR}_{50 \mathrm{~ms}}$ median, $1.37 ; n=8 ; p>0.05$, Mann-Whitney). In contrast, intrastriatal stimulation evoked EPSCs in striatopallidal MSNs that had significantly lower PPRs than at corticostriatal synapses at short interstimulus intervals (Fig. $3 C-F$ ) (corticostriatal $\mathrm{PPR}_{50 \mathrm{~ms}}$ median, 1.25; intrastriatal $\mathrm{PPR}_{50}$ ms median, $0.86 ; n=8 ; p<0.01$; Mann-Whitney). Intrastriatal stimulation yielded PPRs that were significantly lower in striatopallidal MSNs than in straitonigral MSNs (Fig. 3E,F) (stratiatopallidal, intrastriatal $\mathrm{PPR}_{50 \mathrm{~ms}}$ median, 0.86; striatonigral, intrastriatal $\mathrm{PPR}_{50 \mathrm{~ms}}$ median, $1.37 ; n=8 ; p<0.01$, Mann-Whitney). These results confirm that intrastriatal stimulation yields a more complicated response pattern than selective stimulation of either corticostriatal or thalamostriatal fibers. As a consequence, none of the subsequent experiments used this approach.

\section{Short-term plasticity is not dependent on AMPA receptor desensitization}

Both postsynaptic and presynaptic mechanisms can contribute to paired-pulse responses (Choi and Lovinger, 1997; Chen et al., the corticostriatal EPSCs (cortical stimulation, $+\mathrm{CTZ} \tau_{\text {decay }}$ median, $19.6 \mathrm{~ms} ; n=10$; thalamic stimulation, $+\mathrm{CTZ} \tau_{\text {decay }}$ median, $27.2 \mathrm{~ms} ; n=5$; $p<0.05$, Mann-Whitney). This suggests that AMPA receptor desensitization was a factor at thalamostriatal synapses. However, the absence of a change in the PPR in the presence of CTZ argues that it is not a major factor in determining short-term plasticity.

\section{$\mathrm{Sr}^{2+}$-induced asynchronous release differs at corticostriatal and thalamostriatal synapses}

Another strategy that is commonly used to probe synaptic properties is to record mEPSCs. To obtain a picture of quantal events at MSN corticostriatal and thalamostriatal synapses, extracellular $\mathrm{Ca}^{2+}$ was replaced with $\mathrm{Sr}^{2+}$ and each pathway was stimulated; $\mathrm{Sr}^{2+}$ that enters through $\mathrm{Ca}^{2+}$ channels during the initial volley lingers in the terminal, causing asynchronous exocytosis of vesicles not fused during the initial event (Goda and Stevens, 1994). With this approach ( $2 \mathrm{~mm} \mathrm{Sr}^{2+} / 0 \mathrm{Ca}^{2+}$ in the bathing ACSF), corticostriatal and thalamostriatal quantal events could be stud- 
ied in the same MSN (Fig. 5A,B). After cortical stimulation, the modal frequency of asynchronous, quantal EPSCs (qEPSCs) was near $30 \mathrm{~Hz}$ (Fig. $5 C)(31 \pm 2.1 \mathrm{~Hz} ; n>$ 500 sweeps from 16 cells). In contrast, qEPSC frequency after thalamic stimulation was approximately one-half of this value (Fig. $5 C)(17.5 \pm 1.3 \mathrm{~Hz} ; n>300$ sweeps from 16 cells; $p<0.001$, MannWhitney). This difference is consistent with there being a relatively higher probability of transmitter release at the thalamostriatal synapses than at corticostriatal synapses, in agreement with the differences in PPR. In contrast, there were no significant differences in amplitude or kinetics of the qEPSCs evoked by cortical or thalamic stimulation (Fig. 5E,F) (cortical stimulation, amplitude, $12.7 \pm 0.31 \mathrm{pA}$; $10-90 \%$ rise time, $1.9 \pm 0.15 \mathrm{~ms}$; decay time, $4.8 \pm 0.3 \mathrm{~ms}$; thalamic stimulation, amplitude, $12.1 \pm 0.34 \mathrm{pA} ; 10-90 \%$ rise time, $2.3 \pm 0.19 \mathrm{~ms}$; decay time, $4.67 \pm$ $0.48 \mathrm{~ms} ; p>0.05$, Mann-Whitney), indicating that vesicle size and postsynaptic AMPA receptor complements at the two synapses were similar.

\section{Variance analysis suggests a higher release probability at thalamostriatal synapses}

One way of manipulating the probability of release at presynaptic terminals is to change the concentration of $\mathrm{Ca}^{2+}$ in the bathing medium. Lowering the extracellular $\mathrm{Ca}^{2+}$ concentration to $0.5 \mathrm{~mm}$ from 2 mM decreased EPSC amplitude and significantly increased the PPR at both thalamostriatal synapses (Fig. 6A-C) (thalamostriatal $\mathrm{PPR}_{50 \mathrm{~ms}}$ with $2 \mathrm{mM} \mathrm{Ca}^{2+}$ median, 0.85 ; thalamostriatal $\mathrm{PPR}_{50 \mathrm{~ms}}$ with $0.5 \mathrm{mM} \mathrm{Ca}^{2+}$ median, $1.81 ; n=8 ; p<0.01$, Wilcoxon signed rank) and corticostriatal synapses (Fig. $6 D-F$ ) (corticostriatal PPR $50 \mathrm{~ms}$ with $2 \mathrm{mM} \mathrm{Ca}^{2+}$ median, 1.24 ; corticostriatal $\mathrm{PPR}_{50 \mathrm{~ms}}$ with $0.5 \mathrm{mM} \mathrm{Ca}{ }^{2+}$ median, $2.17 ; n=9 ; p<$ 0.001 , Wilcoxon signed rank). Elevating the extracellular $\mathrm{Ca}^{2+}$ concentration to $4 \mathrm{~mm}$ increased EPSC amplitude but decreased the PPR at both corticostriatal and thalamostriatal synapses (Fig. $6 A-F$ ) (thalamostriatal $\mathrm{PPR}_{50 \mathrm{~ms}}$ with $2 \mathrm{mM} \mathrm{Ca}^{2+}$ median, 0.85; thalamostriatal $\mathrm{PPR}_{50 \mathrm{~ms}}$ with $4 \mathrm{mM} \mathrm{Ca}^{2+}$ median, $0.63 ; n=8$; $p<0.01$, Wilcoxon signed rank; corticostriatal $\mathrm{PPR}_{50 \mathrm{~ms}}$ with 2 mM Ca ${ }^{2+}$ median, 1.24; corticostriatal $\mathrm{PPR}_{50 \mathrm{~ms}}$ with $4 \mathrm{mM} \mathrm{Ca}^{2+}$ median, $0.88 ; n=9 ; p<0.01$, Wilcoxon signed rank).

Although consistent with the proposition that the differences in PPR were governed by presynaptic release probability $\left(P_{\mathrm{r}}\right)$, these results do not allow a quantitative estimate of this parameter to be made. To this end, variance-mean analysis was used to obtain an estimate of $P_{\mathrm{r}}$ at each glutamatergic synapse (Clements and Silver, 2000). Corticostriatal and thalamostriatal EPSCs were measured in the presence of the NMDA receptor antagonist D-APV $(50 \mu \mathrm{M})$ in low $(0.5 \mathrm{~mm})$, intermediate $(2.0 \mathrm{mM})$, and high $(4.0 \mathrm{~mm})$ external $\mathrm{Ca}^{2+}$ concentrations. The variance of evoked EPSCs was plotted against mean amplitude and then fitted with parabolic function (see Materials and Methods) (Fig. 6G,H). The parameters of the fitted function provide an estimate of $P_{\mathrm{r}}$ and quantal amplitude $(Q)$. The estimated $Q$ at thalamostriatal and corticostriatal synapses was not significantly different (thalamostriatal, $Q$ median, $7.4 \mathrm{pA}$; corticostriatal, $Q$ median, $6.8 \mathrm{pA} ; n=7$; $p>0.05$, Wilcoxon signed rank), in agreement with the asynchronous release experiments in $\mathrm{Sr}^{2+}$. However, the estimate of $P_{\mathrm{r}}$ was significantly higher at thalamostriatal synapses (Fig. $6 \mathrm{H}$ ) (thalamostriatal, $P_{\mathrm{r}}$ median, 0.72 ; corticostriatal, $P_{\mathrm{r}}$ median, 0.42 ; $n=7 ; p<0.05$, Wilcoxon signed rank).

Corticostriatal and thalamostriatal synapses differ in NMDA/ AMPA ratio and NR2B/NMDA ratio

Another important feature of glutamatergic synapses is the relative abundance of AMPA and NMDA receptors in the postsynaptic membrane. To provide some information about this feature, the NMDA receptor-mediated synaptic currents $\left(V_{\mathrm{hp}}=\right.$ $+40 \mathrm{mV}$ ) and AMPA receptor-mediated synaptic currents $\left(V_{\mathrm{hp}}\right.$ $=+40 \mathrm{mV}$ ) at corticostriatal and thalamostriatal synapses were measured in the same MSN (Fig. $7 A, B$ ). In striatopallidal MSNs, the ratio of peak NMDA to peak AMPA currents (NMDA/ AMPA) was larger at corticostriatal synapses than at thalamostriatal synapses (Fig. 7C) (corticostriatal, $2.75 \pm 0.18, n=21$; thalamostriatal, $2.04 \pm 0.15, n=19 ; p<0.05$, Mann-Whitney). In striatonigral MSNs, the NMDA/AMPA receptor ratios also 

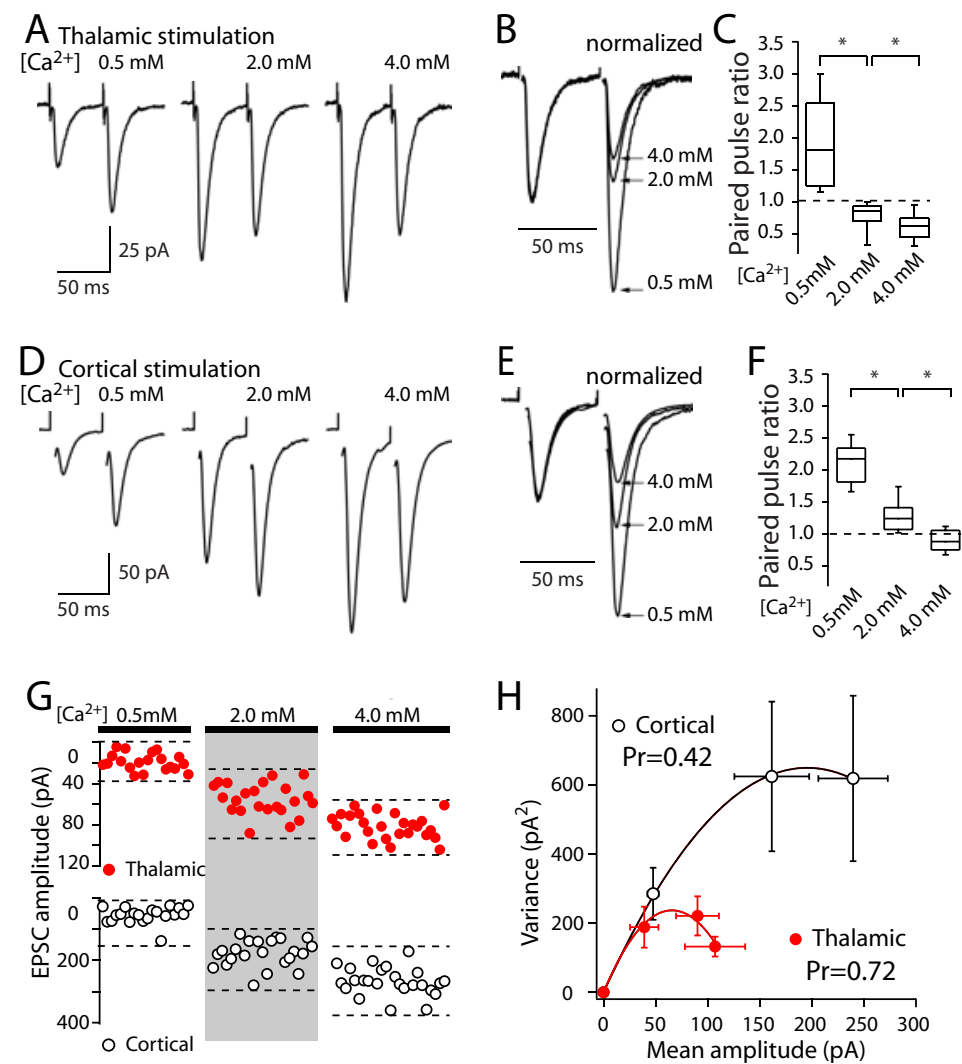

Figure 6. Altering external calcium concentration affects PPRs and synaptic variance, indicating a higher release probability at thalamostriatal synapses. $\boldsymbol{A}$, Paired-pulse thalamic stimulation responses in $0.5 \mathrm{~mm} \mathrm{Ca}{ }^{2+} / 2.5 \mathrm{~mm} \mathrm{Mg}^{2+}, 2 \mathrm{~mm} \mathrm{Ca}{ }^{2+} / 1 \mathrm{~mm}$ $\mathrm{Mg}^{2+}$, and $4 \mathrm{~mm} \mathrm{Ca}{ }^{2+} / 0.5 \mathrm{~mm} \mathrm{Mg}^{2+}$ external solutions. $\boldsymbol{B}$, Normalized thalamostriatal EPSCs elicited by paired-pulse stimulation. C, Box-plot summary of thalamostriatal PPRs at ISI of $50 \mathrm{~ms}$ in different external calcium solutions. D, Paired-pulse cortical stimulation responses in the same recording conditions as in $\boldsymbol{A}$. $\boldsymbol{E}$, Normalized corticostriatal EPSCs elicited by paired-pulse stimulation. F, Box-plot summary of corticostriatal PPRs at ISI of $50 \mathrm{~ms}$ in different external calcium solutions. $\mathbf{G}$, Plot of individual evoked EPSC amplitude for thalamic stimulation in different calcium/magnesium ratio external solution recording conditions (top) and individual evoked EPSC amplitude for cortical stimulation in the same recording conditions (bottom). $\boldsymbol{H}$, Average variance-mean curve for thalamostriatal EPSCs (red circle; $n=7$ cells) and corticostriatal EPSCs (open circle; $n=7$ cells). Data points were fit with a parabola (see Materials and Methods). At $2 \mathrm{~mm} \mathrm{Ca}^{2+} / 1 \mathrm{~mm} \mathrm{Mg}^{2+}$, the estimated release probability was 0.72 for thalamostriatal synapses and 0.42 for corticostriatal synapses. Error bars indicate SEM. Asterisks indicate statistical significance.

were higher at corticostriatal synapses (Fig. 7C) (corticostriatal, $2.84 \pm 0.17, n=19$; thalamostriatal, $2.25 \pm 0.23, n=13$; MannWhitney, $p<0.05$ ), but not significantly different from those in striatopallidal MSNs (Fig. 7C) ( $p>0.05$, Mann-Whitney).

Ifenprodil $(3 \mu \mathrm{M})$ was used to ascertain the component of total NMDA EPSC carried by NR2B-containing NMDA receptors. Interestingly, thalamostriatal synapses had a relatively larger NR2B receptor current than did corticostriatal synapses (Fig. 7D) in both striatopallidal and striatonigral MSNs (Fig. 7E,F) (striatopallidal, corticostriatal median, $0.25 ; n=13$; thalamostriatal median, 0.42 ; $n=9$; striatonigral, corticostriatal median, $0.26 ; n=12$; thalamostriatal median, 0.39; $n=6$; $p<0.05$, Mann-Whitney).

\section{Cortical and thalamic stimulation evoked distinct patterns of MSN spiking}

In the experiments described thus far, the influence of postsynaptic dendritic mechanisms on the synaptic responses has been minimized by loading cells with $\mathrm{Cs}^{+}$(to block $\mathrm{K}^{+}$channels) and voltage clamping the soma. To get a better idea of how the differences in corticostriatal and thalamostriatal synapses are translated to postsynaptic depolarization and spiking, striatopallidal MSNs were recorded in the cell-attached recording configuration at near- physiological temperature $\left(32-34^{\circ} \mathrm{C}\right)$. A train of 10 stimuli at $50 \mathrm{~Hz}$ was delivered to the cortex every $40 \mathrm{~s}$. The stimulus intensity at each site was adjusted to evoke at least one spike in more than half of the trials. In agreement with the facilitating EPSC response pattern seen with stimulus trains, the probability (Pr) that cortical stimulation would evoke a spike in this paradigm rose after the first stimulus and then plateaued (Fig. $8 A, G$ ) $(\operatorname{Pr}=0.16 \pm 0.06$ for the first stimulus, $0.32 \pm$ 0.10 for the 10 th stimulus; $n=11$ ). In the contrast, the probability of spiking after thalamic stimulation was highest for the first stimulus and then steadily declined (Fig. $8 B, G)(\operatorname{Pr}=$ $0.65 \pm 0.08$ for the first stimulus; $n=11 ; p<$ 0.01 compared with that of cortical stimulation, Mann-Whitney; $\operatorname{Pr}=0.04 \pm 0.05$ for the 10 th stimulus; $n=11 ; p<0.05$ compared with that of cortical stimulation, Mann-Whitney)

To then assess how the underlying synaptic events were contributing to this pattern, the membrane at the tip of the electrode was ruptured and the soma was voltage clamped at $-70 \mathrm{mV}$. As expected, cortical stimulation yielded EPSCs that initially grew in size (Fig. $8 C$ ), whereas thalamic stimulation yielded EPSCs that rapidly fell in size (Fig. 8D). To engage the postsynaptic mechanisms, the voltage clamp was discontinued and transmembrane voltage was allowed to fluctuate. Now, cortical stimulation generated a postsynaptic depolarization that grew and then was maintained with little subsequent decline (Fig. 8E,H) (peak depolarization median, 113.6 at third stimulus; least depolarization median, $82.0 \%$ at eighth stimulus; $n=8 ; p>0.05$, Mann-Whitney). In contrast, repetitive thalamic stimulation generated a postsynaptic depolarization that steadily declined in amplitude (Fig. $8 F, H$ ) (median, $45.6 \%$ at the 10 th thalamic stimulus; $n=$ $6 ; p<0.01$ compared with the 10th cortical stimulus, Mann-Whitney).

\section{Discussion}

The major finding of this study was that short-term plasticity at corticostriatal synapses formed on MSNs was significantly different from that at thalamostriatal synapses formed on the same neuron. Corticostriatal synapses displayed paired-pulse facilitation attributable to a low basal quantal release probability at presynaptic terminals. In contrast, thalamostriatal synapses displayed a prominent paired-pulse depression attributable to a high release probability at presynaptic terminals. These synaptic features were indistinguishable in striatopallidal and striatonigral MSNs, and translated into distinct patterns of spiking in response to repetitive stimulation of each pathway.

Thalamostriatal axons are preserved in parahorizontal slices The principal neurons of the striatum, MSNs, receive convergent glutamatergic inputs from both cortex and thalamus (Wojcik et al., 2004). Rather than being a minor contributor, thalamostriatal 


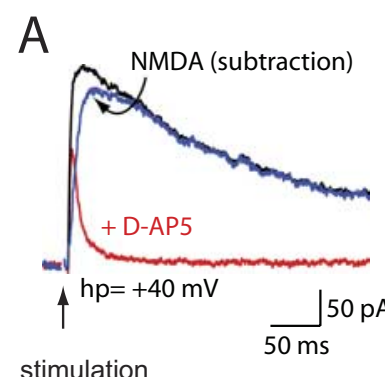

D

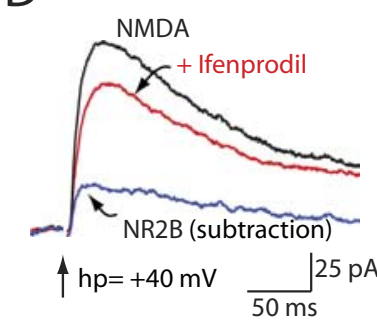

stimulation

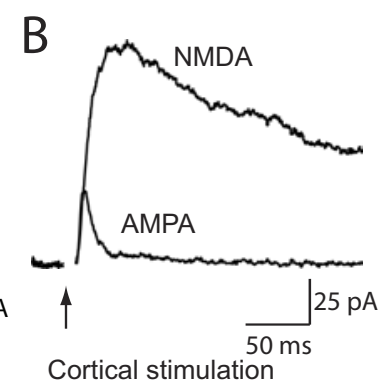

$\mathrm{E}$

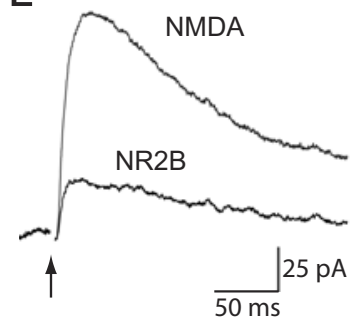

Cortical stimulation
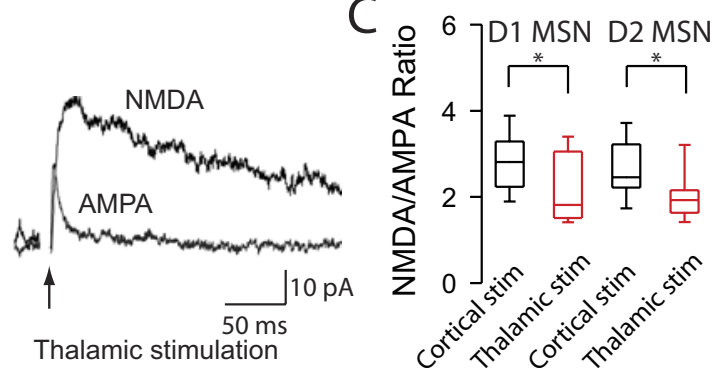

$\mathrm{F}$

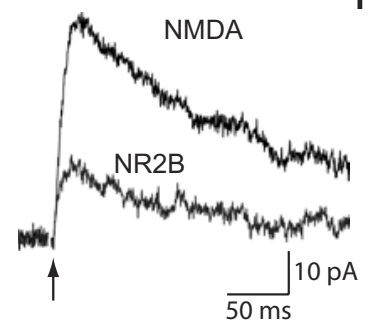

Thalamic stimulation

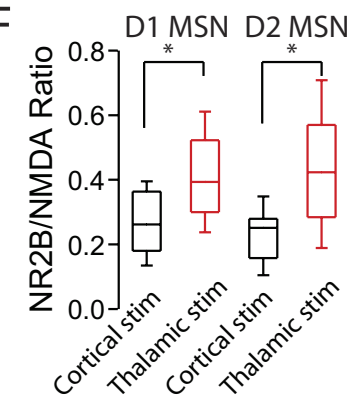

Figure 7. Corticostriatal and thalamostriatal synapses differ in NMDA/AMPA ratio and NR2B/NMDA ratio. $A, D$, Representative traces demonstrating how NMDA, AMPA and NR2B traces were constructed. Total EPSC traces were elicited by cortical or thalamic stimulation while holding MSNs at $+40 \mathrm{mV}$. $\boldsymbol{B}$, Representative traces of NMDA and AMPA EPSCs elicited by cortical and thalamic stimulation. C, Box-plot summary of NMDA/AMPA ratios demonstrating a significantly smaller NMDA/AMPA ratio in corticostriatal synapses compared with thalamostriatal synapses. Corticostriatal and thalamostriatal NMDA/AMPA ratios were not significantly different between striatopallidal and striatonigral MSNs. $\boldsymbol{E}$, Representative traces of NR2B and NMDA EPSCs elicited by cortical and thalamic ctimulation. $F$, Box-plot summary of NR2B/NMDA ratios demonstrating significantly larger NR2B/NMDA ratios in thalamostriatal synapses compared with corticostriatal synapses. Corticostriatal and thalamostriatal NR2B/NMDA ratios were not significantly different between striatopallidal and striatonigral MSNs. Asterisks indicate statistical significance.

synapses constitute $\sim 40 \%$ of the glutamatergic synapses formed on the dendrites of MSNs (Smith et al., 2004). The thalamic projection originates largely from the intralaminar thalamic nuclei (Berendse and Groenewegen, 1990; Smith et al., 2004), which includes centromedian parafascicular nuclei, but other thalamic nuclei, including the ventrolateral nuclei, also send projections to the striatum (Hoshi et al., 2005).

Although anatomically prominent, virtually nothing is known about the physiological properties of these synapses. Because thalamostriatal axons travel horizontally and laterally toward the striatum, very few thalamostriatal axons remain connected with their cell bodies in conventional coronal or parasagittal slice preparations (Kawaguchi et al., 1989; Deschenes et al., 1996). Moreover, these axons intermingle with those of corticostriatal axons within the striatum, making selective stimulation within the striatum impossible. To make matters worse, in coronal slices of the brain, the most widely used slice in vitro, corticostriatal axons are also disconnected from their cell bodies, making selective stimulation of corticostriatal axons problematic as well (Kawaguchi et al., 1989). This limitation undermines the common inference that plasticity observed at glutamatergic synapses of MSNs studied in this preparation is in fact plasticity of corticostriatal synapses, rather than that of thalamostriatal synapses (Calabresi et al., 1992b; Wang et al., 2006; Akopian and Walsh, 2007; Kreitzer and Malenka, 2007). To overcome this limitation, parahorizontal slices of the brain were made that preserved both corticostriatal and thalamostriatal connectivity, at least for a subset of axons, allowing unequivocal activations of one or the other projection (Smeal et al., 2007).

\section{Corticostriatal and thalamostriatal synapses have distinct short-term plasticity}

Anatomical studies have shown that corticostriatal and thalamostriatal glutamatergic synapses are similar morphologically and intermingled along the dendrites of MSNs (Smith et al., 2004; Raju et al., 2006). In agreement with this observation, our data show that the rise time, decay time and size of corticostriatal and thalamostriatal qEPSCs were indistinguishable. However, these synapses did differ in other respects. PPRs at corticostriatal synapses were $>1$ over a range of interstimulus intervals, whereas PPRs were $<1$ at thalamostriatal synapses. Consistent with the inference that the differences in PPR were a reflection of terminal release probability, the frequency of $\mathrm{Sr}^{2+}$-induced asynchronous quantal release at corticostriatal synapses was significantly higher than that at thalamostriatal synapses. Moreover, PPRs were not significantly altered by diminishing AMPA receptor desensitization with CTZ, again implicating presynaptic mechanisms. More direct evidence about release probability came from the effect of changing extracellular $\mathrm{Ca}^{2+}$ concentrations. Not only were PPRs affected in the expected way by changing the $\mathrm{Ca}^{2+}$ concentration, but mean-variance analysis of the synaptic responses (Clements and Silver, 2000; Zucker and Regehr, 2002; Foster and Regehr, 2004) also strongly suggested that the probability of release was higher at thalamostriatal synapses than at corticostriatal synapses formed on the same MSN. The short-term plasticity of corticostriatal and thalamostriatal synapses we observed was very similar to that seen at corticocortical and thalamocortical synapses, suggesting that they reflect a common physiological property of cortical and thalamic projection neurons (Stratford et al., 1996; Gil et al., 1997).

The molecular basis for the difference in release probability is not known. Corticostriatal and thalamostriatal neurons express different vesicular glutamate transporter proteins: vGluT1 and vGluT2, respectively (Kaneko et al., 2002; Fremeau et al., 2004). These two transporter proteins are differentially expressed in cerebellar parallel and climbing fiber terminals where there is a similar divergence in release probability (Miyazaki et al., 2003). Whether the 


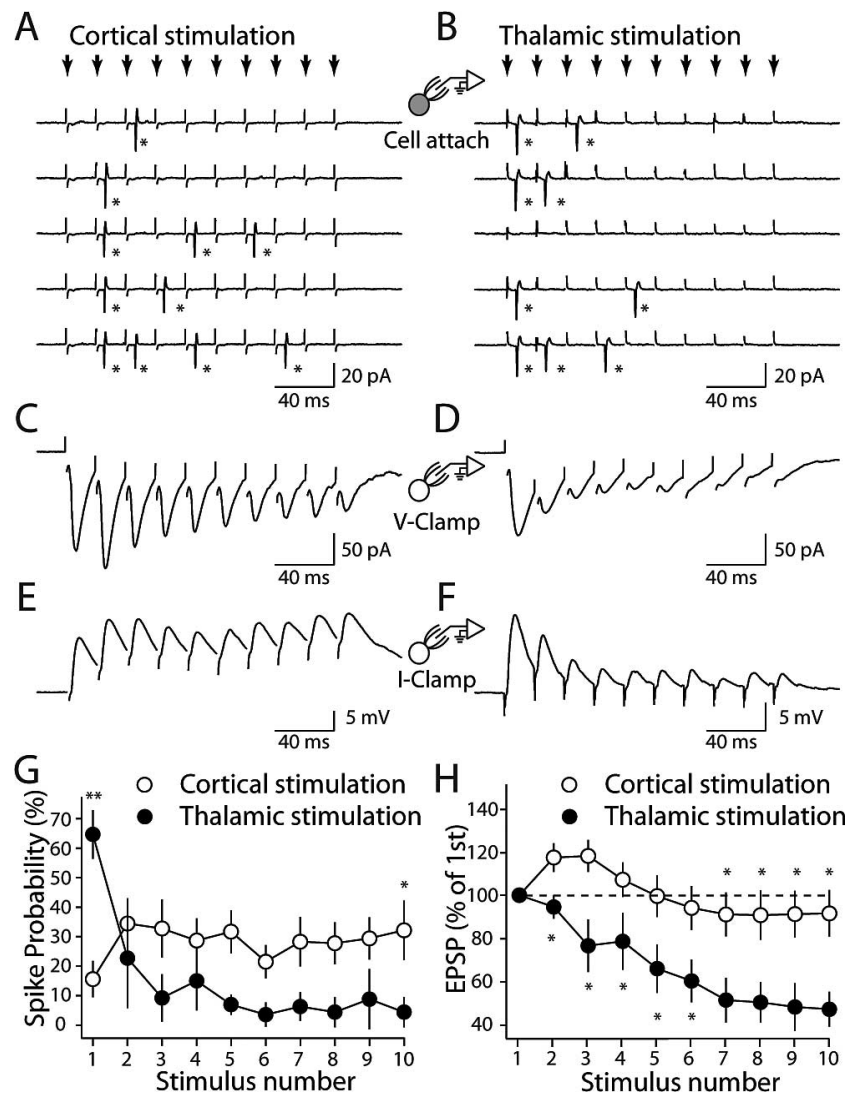

Figure 8. Cortical and thalamic stimulation evoke different patterns of spiking in MSNs. $\boldsymbol{A}, \boldsymbol{B}$, Cell-attached recordings from a striatopallidal neuron; the response to repetitive cortical and thalamic stimulation (small arrows, $50 \mathrm{~Hz}$ ) at threshold intensity. Stars, Action potentials. $\boldsymbol{C}-\boldsymbol{F}$, The same cell in $\boldsymbol{A}$ and $\boldsymbol{B}$ was recorded in whole-cell voltage-clamp (V-Clamp) and current-clamp (I-Clamp) mode. G, Summary graph shows spike probability plotted against stimulus number for cortical and thalamic stimulation in striatopallidal neurons. $\boldsymbol{H}$, Summary graph showing EPSP amplitude as a percentage of the first EPSP amplitude plotted against stimulus number. Asterisks indicate statistical significance. Error bars indicate SEM.

expression of these proteins is causally linked to release probability is not clear, but it is clear that vGluT expression is a marker of synaptic phenotype (Fremeau et al., 2004; Wojcik et al., 2004).

Although consistent with work in other brain regions, our results are at odds with a recent report that thalamostriatal synapses are facilitating (Smeal et al., 2007). The origin of the discrepancy is not clear at this point. Only a single interstimulus interval $(200 \mathrm{~ms})$ was examined in this study, a duration at which, in our hands, the differences between corticostriatal and thalamostriatal PPRs was small. It is possible that the properties of thalamostriatal terminals are heterogeneous and that, although the slice preparation used in our studies was very similar, our stimulation protocol activated a different set of thalamostriatal axons.

\section{Short-term plasticity is independent of MSN phenotype}

The short-term plasticity at corticostriatal and thalamostriatal synapses was indistinguishable in striatonigral and striatopallidal MSNs identified by their expression of GFP controlled by DA receptor promoters. GFP has been shown previously to faithfully report MSN phenotype (Day et al., 2006). At first glance, these results seem at odds with a recent report that properties of the glutamatergic synapses formed on striatopallidal and striatonigral neurons differ (Kreitzer and Malenka, 2007). However, this study relied on intrastriatal microstimulation that would not readily distinguish corticostriatal and thalamostriatal axons. Using a similar stimulation paradigm, we were able to reproduce these results. However, the reasons for the differential response in the two MSN populations is not clear. It is possible that thalamostriatal axons innervating striatopallidal MSNs have a lower electrical threshold, giving these MSNs the appearance of being dominated by this input. There is evidence that thalamic neurons innervated by the cerebellum preferentially innervate striatopallidal MSNs (Hoshi et al., 2005). That said, grading the intrastriatal stimulation intensity did not systematically change PPR properties in our hands (data not shown). Another possibility is that intrastriatal stimulation induces the release of neuromodulators, like dopamine and acetylcholine, that preferentially target striatonigral MSN synapses, reducing their average release probability. Stimulation of the corticostriatal or thalamostriatal afferent fibers alone is much less likely to engage secondary modulatory mechanisms, giving a truer picture of basal synaptic properties.

\section{Corticostriatal and thalamostriatal synapses have different glutamate receptor composition}

In addition to differing in short-term plasticity, corticostriatal and thalamostriatal synapses diverged in their relative expression of AMPA and NMDA receptors. The amplitude of currents carried by NMDA receptors relative to that carried by AMPA receptors (NMDA/AMPA ratio) was significantly greater at corticostriatal synapses than at thalamostriatal synapses. This was true in both striatopallidal and striatonigral MSNs. This finding has several implications. First, the relative abundance of NMDA receptors at corticostriatal synapses should synergize with the facilitating character of the presynaptic terminal to promote more prolonged and robust dendritic depolarization in response to bursts of afferent activity. This could be particularly important in transitions from hyperpolarized down states to depolarized up states that occur in MSNs in response to temporally and spatially coordinated cortical activity (Stern et al., 1997; Vergara et al., 2003). Second, the greater expression of NMDA receptors at corticostriatal synapses should bias them toward the induction of long-term potentiation (LTP) in response to pairing of high-frequency afferent stimulation and postsynaptic depolarization. The induction of LTP at MSN glutamatergic synapses is dependent on NMDA receptors (Calabresi et al., 1992a), as at many other synapses (Malenka and Bear, 2004). Thus, although the common inference that in coronal slices pairing of high-frequency stimulation of the white matter overlying the striatum with depolarization of MSNs induces LTP at corticostriatal synapses is not justified on the basis of the stimulation paradigm (because in this preparation white matter stimulation activates both corticostriatal and thalamostriatal fibers), it might be correct largely because LTP is more inducible at corticostriatal synapses than thalamostriatal synapses. The relatively larger contribution of NR2A-containing receptors to the NMDA currents at corticostriatal synapses also is consistent with this inference (Bartlett et al., 2007). However, providing unequivocal evidence on this point will require additional study in a prepara- 
tion like the one used here, where the susceptibility of each input to long-term plasticity can be determined in an identified MSN.

\section{The functional consequences of corticostriatal and thalamostriatal plasticity}

The physiological divergence of corticostriatal and thalamostriatal synapses is consistent with what is known about the functional properties of these two systems. Corticostriatal projections are hypothesized to be involved in cognitive and motivational aspects of goal-directed behavior and associative learning (Graybiel, 2000). One manifestation of this signaling is the regulation of state transitions in MSNs. It has also been suggested that NMDA receptors are critical for the up-state transition and membrane voltage oscillations (Vergara et al., 2003). In vivo, MSN transitions to depolarized up-states are closely linked to those of cortical pyramidal neurons (Wilson, 1993). The facilitating character of the presynaptic terminal and relatively larger NMDA receptor complement of corticostriatal synapses makes them perfectly suited to the establishment and maintenance of depolarized upstates. In contrast, thalamostriatal signaling is thought to convey information about the occurrence of salient sensory events that play a role in arousal and attention (Matsumoto et al., 2001). The thalamostriatal synapse, with a high initial release probability that rapidly falls with successive stimulation, appears well suited to the role of conveying precisely timed, episodic signals.

\section{References}

Akopian G, Walsh JP (2007) Reliable long-lasting depression interacts with variable short-term facilitation to determine corticostriatal paired-pulse plasticity. J Physiol (Lond) 580:225-240.

Bartlett TE, Bannister NJ, Collett VJ, Dargan SL, Massey PV, Bortolotto ZA, Fitzjohn SM, Bashir ZI, Collingridge GL, Lodge D (2007) Differential roles of NR2A and NR2B-containing NMDA receptors in LTP and LTD in the CA1 region of twoweek old rat hippocampus. Neuropharmacology 52:60-70.

Berendse HW, Groenewegen HJ (1990) Organization of the thalamostriatal projections in the rat, with special emphasis on the ventral striatum. J Comp Neurol 299:187-228.

Calabresi P, Pisani A, Mercuri NB, Bernardi G (1992a) Long-term potentiation in the striatum is unmasked by removing the voltage-dependent magnesium block of NMDA receptor channels. Eur J Neurosci 4:929-935.

Calabresi P, Maj R, Pisani A, Mercuri NB, Bernardi G (1992b) Long-term synaptic depression in the striatum: physiological and pharmacological characterization. J Neurosci 12:4224-4233.

Chen C, Blitz DM, Regehr WG (2002) Contributions of receptor desensitization and saturation to plasticity at the retinogeniculate synapse. Neuron 33:779-788.

Choi S, Lovinger DM (1997) Decreased probability of neurotransmitter release underlies striatal long-term depression and postnatal development of corticostriatal synapses. Proc Natl Acad Sci USA 94:2665-2670.

Clements JD, Silver RA (2000) Unveiling synaptic plasticity: a new graphical and analytical approach. Trends Neurosci 23:105-113.

Day M, Wang Z, Ding J, An X, Ingham CA, Shering AF, Wokosin D, Ilijic E, Sun Z, Sampson AR, Mugnaini E, Deutch AY, Sesack SR, Arbuthnott GW, Surmeier DJ (2006) Selective elimination of glutamatergic synapses on striatopallidal neurons in Parkinson disease models. Nat Neurosci 9:251-259.

Deschenes M, Bourassa J, Doan VD, Parent A (1996) A single-cell study of the axonal projections arising from the posterior intralaminar thalamic nuclei in the rat. Eur J Neurosci 8:329-343.

Foster KA, Regehr WG (2004) Variance-mean analysis in the presence of a rapid antagonist indicates vesicle depletion underlies depression at the climbing fiber synapse. Neuron 43:119-131.

Fremeau Jr RT, Kam K, Qureshi T, Johnson J, Copenhagen DR, StormMathisen J, Chaudhry FA, Nicoll RA, Edwards RH (2004) Vesicular glutamate transporters 1 and 2 target to functionally distinct synaptic release sites. Science 304:1815-1819.
Gerfen CR (1989) The neostriatal mosaic: striatal patch-matrix organization is related to cortical lamination. Science 246:385-388.

Gil Z, Connors BW, Amitai Y (1997) Differential regulation of neocortical synapses by neuromodulators and activity. Neuron 19:679-686.

Goda Y, Stevens CF (1994) Two components of transmitter release at a central synapse. Proc Natl Acad Sci USA 91:12942-12946.

Graybiel AM (2000) The basal ganglia. Curr Biol 10:R509-R511.

Heintz N (2001) BAC to the future: the use of BAC transgenic mice for neuroscience research. Nat Rev Neurosci 2:861-870.

Hoshi E, Tremblay L, Feger J, Carras PL, Strick PL (2005) The cerebellum communicates with the basal ganglia. Nat Neurosci 8:1491-1493.

Kaneko T, Fujiyama F, Hioki H (2002) Immunohistochemical localization of candidates for vesicular glutamate transporters in the rat brain. J Comp Neurol 444:39-62.

Kawaguchi Y, Wilson CJ, Emson PC (1989) Intracellular recording of identified neostriatal patch and matrix spiny cells in a slice preparation preserving cortical inputs. J Neurophysiol 62:1052-1068.

Kreitzer AC, Malenka RC (2007) Endocannabinoid-mediated rescue of striatal LTD and motor deficits in Parkinson's disease models. Nature 445:643-647.

Lei W, Jiao Y, Del Mar N, Reiner A (2004) Evidence for differential cortical input to direct pathway versus indirect pathway striatal projection neurons in rats. J Neurosci 24:8289-8299.

Malenka RC, Bear MF (2004) LTP and LTD: an embarrassment of riches. Neuron 44:5-21.

Matsumoto N, Minamimoto T, Graybiel AM, Kimura M (2001) Neurons in the thalamic CM-Pf complex supply striatal neurons with information about behaviorally significant sensory events. J Neurophysiol 85:960-976.

Miyazaki T, Fukaya M, Shimizu H, Watanabe M (2003) Subtype switching of vesicular glutamate transporters at parallel fibre-Purkinje cell synapses in developing mouse cerebellum. Eur J Neurosci 17:2563-2572.

Minamimoto T, Kimura M (2002) Participation of the thalamic CM-Pf complex in attentional orienting. J Neurophysiol 87:3090-3101.

Raju DV, Shah DJ, Wright TM, Hall RA, Smith Y (2006) Differential synaptology of vGluT2-containing thalamostriatal afferents between the patch and matrix compartments in rats. J Comp Neurol 499:231-243.

Sidibe M, Smith Y (1996) Differential synaptic innervation of striatofugal neurones projecting to the internal or external segments of the globus pallidus by thalamic afferents in the squirrel monkey. J Comp Neurol 365:445-465.

Smeal RM, Gaspar RC, Keefe KA, Wilcox KS (2007) A rat brain slice preparation for characterizing both thalamostriatal and corticostriatal afferents. J Neurosci Methods 159:224-235.

Smith Y, Raju DV, Pare JF, Sidibe M (2004) The thalamostriatal system: a highly specific network of the basal ganglia circuitry. Trends Neurosci 27:520-527.

Stern EA, Kincaid AE, Wilson CJ (1997) Spontaneous subthreshold membrane potential fluctuations and action potential variability of rat corticostriatal and striatal neurons in vivo. J Neurophysiol 77:1697-1715.

Stratford KJ, Tarczy-Hornoch K, Martin KA, Bannister NJ,JackJJ (1996) Excitatory synaptic inputs to spiny stellate cells in cat visual cortex. Nature 382:258-261.

Surmeier DJ, Song WJ, Yan Z (1996) Coordinated expression of dopamine receptors in neostriatal medium spiny neurons. J Neurosci 16:6579-6591.

Vergara R, Rick C, Hernandez-Lopez S, Laville JA, Guzman JN, Galarraga E, Surmeier DJ, Bargas J (2003) Spontaneous voltage oscillations in striatal projection neurons in a rat corticostriatal slice. J Physiol (Lond) 553:169-182.

Wang Z, Kai L, Day M, Ronesi J, Yin HH, Ding J, Tkatch T, Lovinger DM, Surmeier DJ (2006) Dopaminergic control of corticostriatal long-term synaptic depression in medium spiny neurons is mediated by cholinergic interneurons. Neuron 50:443-452.

Wilson CJ (1993) The generation of natural firing patterns in neostriatal neurons. Prog Brain Res 99:277-297.

Wilson CJ (2004) Basal ganglia. In: The synaptic organization of the brain, Ed 5 (Shepherd GM, ed), pp 361-414. Oxford: Oxford UP.

Wojcik SM, Rhee JS, Herzog E, Sigler A, Jahn R, Takamori S, Brose N, Rosenmund C (2004) An essential role for vesicular glutamate transporter 1 (VGLUT1) in postnatal development and control of quantal size. Proc Natl Acad Sci USA 101:7158-7163.

Zucker RS, Regehr WG (2002) Short-term synaptic plasticity. Annu Rev Physiol 64:355-405. 